Article

\title{
In Vivo Measurement of Neurochemical Abnormalities in the Hippocampus in a Rat Model of Cuprizone-Induced Demyelination
}

\author{
Do-Wan Lee ${ }^{1, *,+}{ }^{\mathbb{C}}$, Jae-Im Kwon ${ }^{2}$, Chul-Woong Woo ${ }^{2}$, Hwon Heo ${ }^{3}$, Kyung Won Kim ${ }^{1}{ }^{\mathbb{C}}$, Dong-Cheol Woo ${ }^{2,3}{ }^{\circledR}$, \\ Jeong Kon $\mathrm{Kim}^{1}$ and Dong-Hoon Lee ${ }^{4, *,+(\mathbb{D})}$ \\ 1 Department of Radiology, Asan Medical Center, University of Ulsan College of Medicine, Seoul 05505, Korea; \\ medimash@gmail.com (K.W.K.); kim.jeongkon@gmail.com (J.K.K.) \\ 2 Convergence Medicine Research Center, Asan Institute for Life Sciences, Asan Medical Center, Seoul 05505, \\ Korea; kji1733@naver.com (J.-I.K.); wandj79@hanmail.net (C.-W.W.); dcwoo@amc.seoul.kr (D.-C.W.) \\ 3 Department of Convergence Medicine, Asan Medical Center, University of Ulsan College of Medicine, \\ Seoul 05505, Korea; heohwon@gmail.com \\ 4 Department of Radiation Convergence Engineering, Yonsei University, Wonju 26493, Korea \\ * Correspondence: dwlee.mri@gmail.com (D.-W.L.); dlee1@yonsei.ac.kr (D.-H.L.) \\ + These authors contributed equally to this study.
}

check for updates

Citation: Lee, D.-W.; Kwon, J.-I.; Woo, C.-W.; Heo, H.; Kim, K.-W.; Woo, D.-C.; Kim, J.-K.; Lee, D.-H. In Vivo Measurement of Neurochemical Abnormalities in the Hippocampus in a Rat Model of Cuprizone-Induced Demyelination. Diagnostics 2021, 11, 45. https://doi.org/10.3390/ diagnostics11010045

Received: 18 November 2020 Accepted: 27 December 2020 Published: 30 December 2020

Publisher's Note: MDPI stays neutral with regard to jurisdictional clai$\mathrm{ms}$ in published maps and institutional affiliations.

Copyright: $\odot 2020$ by the authors. Licensee MDPI, Basel, Switzerland. This article is an open access article distributed under the terms and conditions of the Creative Commons Attribution (CC BY) license (https:// creativecommons.org/licenses/by/ $4.0 /)$.

\begin{abstract}
This study quantitatively measured the changes in metabolites in the hippocampal lesions of a rat model of cuprizone-induced demyelination as detected using in vivo $7 \mathrm{~T}$ proton magnetic resonance spectroscopy. Nineteen Sprague Dawley rats were randomly divided into two groups and fed a normal chow diet or cuprizone $(0.2 \%, \mathrm{w} / \mathrm{w})$ for 7 weeks. Demyelinated hippocampal lesions were quantitatively measured using a $7 \mathrm{~T}$ magnetic resonance imaging scanner. All proton spectra were quantified for metabolite concentrations and relative ratios. Compared to those in the controls, the cuprizone-induced rats had significantly higher concentrations of glutamate $(p=0.001)$, gamma-aminobutyric acid $(p=0.019)$, and glutamate + glutamine $(p=0.001)$; however, creatine + phosphocreatine $(p=0.006)$ and myo-inositol $(p=0.001)$ concentrations were lower. In addition, we found that the glutamine and glutamate complex/total creatine $(p<0.001)$, glutamate/total creatine $(p<0.001)$, and GABA/total creatine $(p=0.002)$ ratios were significantly higher in cuprizonetreated rats than in control rats. Our results showed that cuprizone-induced neuronal demyelination may influence the severe abnormal metabolism in hippocampal lesions, and these responses could be caused by microglial activation, mitochondrial dysfunction, and astrocytic necrosis.
\end{abstract}

Keywords: rat brain; demyelination; hippocampus; metabolites; multiple sclerosis

\section{Introduction}

Multiple sclerosis (MS) is a chronic and progressive inflammatory disease of the central nervous system (CNS) [1,2]. The most significant characteristic features of MS are inflammatory lesions, primary demyelination, axonal damage, plaques, microglial activation, mitochondrial dysfunction, and abnormal metabolism [2-4]. In recent years, studies have shown that demyelination affects not only the white matter (WM) in the corpus callosum but also the gray matter (GM), such as that in the cortex, hippocampus, and cerebellum [5,6]. Among these brain regions, the hippocampus plays a pivotal role in learning processes, spatial memory, and the consolidation of long-term memory from short-term memory [7,8]. The hippocampus was chosen as the major target of the present study, since MS patients commonly present with cognitive deficits, often in the form of episodic memory impairments, which might be caused by pathophysiological changes (functional/metabolic abnormalities) in this region [2,9].

To identify key markers of the complex mechanisms in MS, various animal models, including toxin-induced models, have been established [10,11]. In particular, cuprizone 
is a selective and sensitive copper chelating agent that is commonly used to create a toxicity-induced non-autoimmune animal model of MS to assess the pathophysiological processes of cerebral demyelination and remyelination [3]. Cuprizone induces mature oligodendrocyte damage with subsequent demyelination, but it does not damage other cell types in the CNS $[10,11]$. Moreover, previous studies have suggested that the cuprizoneinduced model is reproducible and sustainable for the neurobiological assessment of cerebral demyelination in MS [3,12]. In this study, we used a well-characterized cuprizoneinduced MS model to investigate the neurochemical changes in the hippocampal region.

In vivo magnetic resonance (MR)-based imaging techniques provide a non-invasive method for evaluating various anatomical lesions and structural changes, including focal demyelination, axonal injuries, and inflammation in MS [13]. However, MR-based imaging cannot distinguish between cerebral demyelination, inflammation, and axonal injuries $[13,14]$. Thus, to obtain a better insight into the underlying pathology and evaluate biological signals from the neurochemical compounds involved in MS, there is a need to reflect molecular processes using in vivo MR-based techniques.

In vivo proton MR spectroscopy ( ${ }^{1} \mathrm{H}$ MRS) is a unique method for non-invasive quantification of cerebral neurochemical markers involved in neuromolecular processes [15-17]. High-resolution in vivo ${ }^{1} \mathrm{H}$ MRS at $7 \mathrm{~T}$ allows the assessment of more detailed chemical compounds with higher precision than lower magnetic field strength $[18,19]$. In the in vivo MR spectra, the resonance intensities and total area of metabolites are proportionally represented by the cerebral metabolite concentrations. Furthermore, both the absolute concentration of metabolites and their ratios have been used in numerous human and animal studies [20]. The utility of in vivo ${ }^{1} \mathrm{H}$ MRS has been previously described $[20,21]$.

The aim of this study was to quantitatively examine neurochemical alterations in hippocampal lesions in a rat model of cuprizone-induced demyelination, detected using ${ }^{1} \mathrm{H}$ MRS at $7 \mathrm{~T}$. For this purpose, the present study quantitatively assessed changes in the concentrations and metabolic signal ratios of detectable neurochemical profiles in the hippocampal region of the rat brain.

\section{Materials and Methods}

\subsection{Animals and Cuprizone Intoxication}

All animal experiments were approved by the Institutional Animal Care and Use Committee at the Asan Medical Center, University of Ulsan College of Medicine (No. 2018-13-271). The animal experiments were carried out according to the "Guide for the Care and Use of Laboratory Animals" (NIH Publications No. 80-23, revised 1978).

Nineteen Sprague Dawley rats were purchased (Orient Bio Inc., Seongnam, Kyunggido, Korea) and divided into two groups (control (CTRL) group; $\mathrm{n}=11$, and cuprizoneinduced (CPR) group; $\mathrm{n}=8$ ). The animals were housed in standard plastic cages and maintained on a 12 -h light-dark cycle at an ambient temperature of $23-24^{\circ} \mathrm{C}$. Before the start of the experiments, the animals were allowed free access to food and water for a week. To induce demyelination in the hippocampus, eight CPR rats were fed a milled diet with $0.2 \%$ cuprizone (bis[cyclohexanone]oxaldihydrazone, \#370-81-0, Merck KGaA, Darmstadt, Germany) for 7 weeks, while CTRL rats were maintained on a regular chow diet.

\subsection{In Vivo ${ }^{1} H$ MR Spectroscopy}

The designs of in vivo ${ }^{1} \mathrm{H}$ MRS studies have been previously described [22]. All in vivo MR experiments were performed using a horizontal $7 \mathrm{~T} / 160-\mathrm{mm}$ preclinical MRI scanner (Bruker PharmaScan 70/16, Bruker BioSpin, Ettlingen, Germany) that resonated at $300.32 \mathrm{MHz}$ for ${ }^{1} \mathrm{H}$, equipped with a $400 \mathrm{mT} / \mathrm{m}$ self-shielded gradient system. All data were recorded using a receive-only rat brain surface coil in combination with a 72-mm volume coil for excitation. All animals were anesthetized using a nose cone via spontaneous inhalation of $1-2 \%$ isoflurane in $70 \% \mathrm{~N}_{2} \mathrm{O} / 30 \% \mathrm{O}_{2}$ (flow rate: $1.0 \mathrm{~L} / \mathrm{min}$ ). For the placement of ${ }^{1} \mathrm{H}$ MRS voxel, two-dimensional $\mathrm{T}_{2}$-weighted MR images were acquired as follows: repetition time $(\mathrm{TR})=5250 \mathrm{~ms}$, echo time $(\mathrm{TE})=66 \mathrm{~ms}$, field of 
view $=25 \times 25 \mathrm{~mm}^{2}$, image matrix $=256 \times 256$, echo spacing $=11 \mathrm{~ms}$, average $=2$, and total scan time $=2 \min 48 \mathrm{~s}$ per image plane (axial, sagittal, and coronal). Watersuppressed in vivo proton spectra were acquired from the hippocampal region of the right hemisphere (Figure 1). All parameters were as follows: spin-echo-based point-resolved spectroscopy (PRESS) pulse sequence, variable power and optimized relaxation delays method, volume of interest $(\mathrm{VOI})=2 \times 2 \times 3 \mathrm{~mm}^{3}(12.0 \mu \mathrm{L}), \mathrm{TR}=5000 \mathrm{~ms}, \mathrm{TE}=16.3 \mathrm{~ms}$, spectral width $=5000 \mathrm{~Hz}$, average $=256$, number of data points $=2048$, and total scan time $=23 \min 15 \mathrm{~s}$.

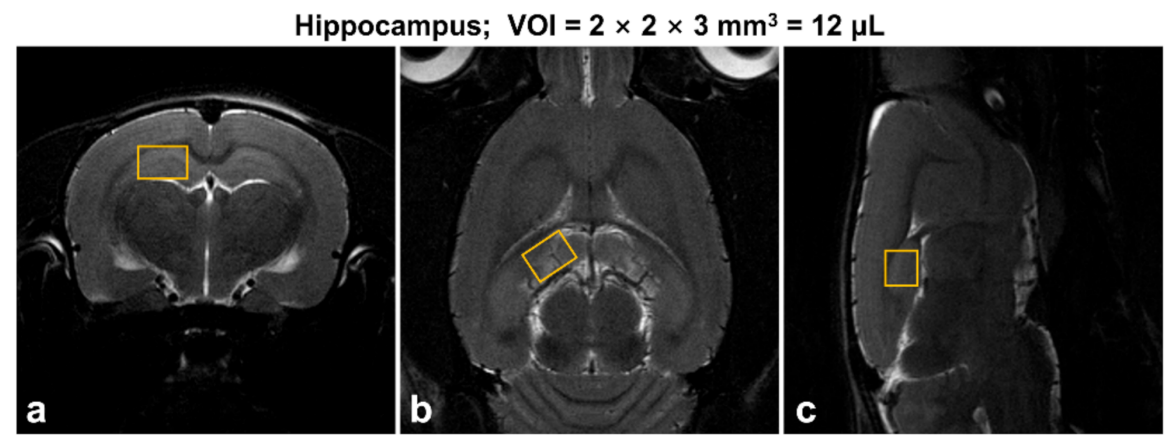

Figure 1. Representative multi-slice T2-weighted magnetic resonance (MR) images: (a) axial, (b) coronal, (c) sagittal, and voxel placement in the hippocampal region (yellow).

\subsection{Spectral Quantification}

Postprocessing of ${ }^{1} \mathrm{H}$ MRS raw data was quantified using a linear combination of models (LCModel, v. 6.3-1D, copyright: Stephen W. Provencher, Stephen Provencher Inc., Oakville, Canada) in a fully automated pipeline. In vivo proton spectra were analyzed using a set of simulated basis sets including 18 metabolites, as follows: Ala, alanine; Asp, aspartate; $\mathrm{Cr}$, creatine; GABA, gamma-aminobutyric acid; Glc, glucose; Glu, glutamate; Gln, glutamine; GSH, glutathione; GPC, glycerophosphocholine; Gly, glycine; Lac, lactate; NAA, N-acetylaspartate; NAAG, N-acetylaspartylglutamate; mIns, myo-inositol; PCh, phosphocholine; PCr, phosphocreatine; sIns, scyllo-inositol; Tau, taurine; tNAA, total $\mathrm{NAA}=\mathrm{NAA}+\mathrm{NAAG}$; Glx, glutamine and glutamate complex = Glu + Gln; tCr, total $\mathrm{Cr}=\mathrm{Cr}+\mathrm{PCr}$; and tCho, total Cho $=\mathrm{GPC}+\mathrm{PCh}$. Eddy current correction in all proton spectra was applied and fitted in the chemical shift range from 4.0 to $0.3 \mathrm{ppm}$. The unsuppressed water signal was used as an internal reference for water scaling, and metabolite concentrations were acquired $(\mu \mathrm{mol} / \mathrm{g})$. Additionally, the relative metabolite levels of Glx, $\mathrm{Glu}$, and GABA were calculated by dividing the $\mathrm{tCr}$ signals and expressed as $\mathrm{Glx} / \mathrm{tCr}$, $\mathrm{Glu} / \mathrm{tCr}$, and GABA/tCr ratios.

An estimate of uncertainty (Cramer-Rao lower bounds (CRLBs)) with frequency domain fitting was provided by the LCModel and expressed as percent standard deviation (\%SD). Individual metabolite signals were used to determine the reliability of the fitting; less than 10\% SD was considered acceptable for Glu, mIns, Tau, tCho, tNAA, tCr, and Glx; less than $20 \%$ SD was acceptable for Cr, PCr, GABA, Gln, and GSH.

\subsection{Statistical Analysis}

All statistical analyses were performed using PASW Statistics 21 (SPSS Inc., IBM Company, Chicago, IL, USA). The metabolite quantification values (absolute concentrations and peak ratio values), spectral quality measurements (signal-to-noise ratio (SNR), and full-width at half-maximum (FWHM)) were normally distributed for all data (KolmogorovSmirnov test of normality, all $p>0.05)$, and independent two-sample $t$-tests were used. Statistical differences were assumed to be significant for $p$-values $<0.05$. 


\section{Results}

Representative high-resolution $7 \mathrm{~T}$ spectra with narrow linewidths from a single voxel of the hippocampal region were obtained throughout the study. In all proton spectra (Figure 2), the average FWHM (Hz) and SNR values estimated using the LCModel in the CTRL and CPR groups were $7.8 \pm 1.0$ and $7.5 \pm 0.8(p=0.552)$ and $13.5 \pm 1.0$ and $14.0 \pm 1.2$ $(p=0.388)$, respectively. All spectral quality values showed no significant differences between the two groups.

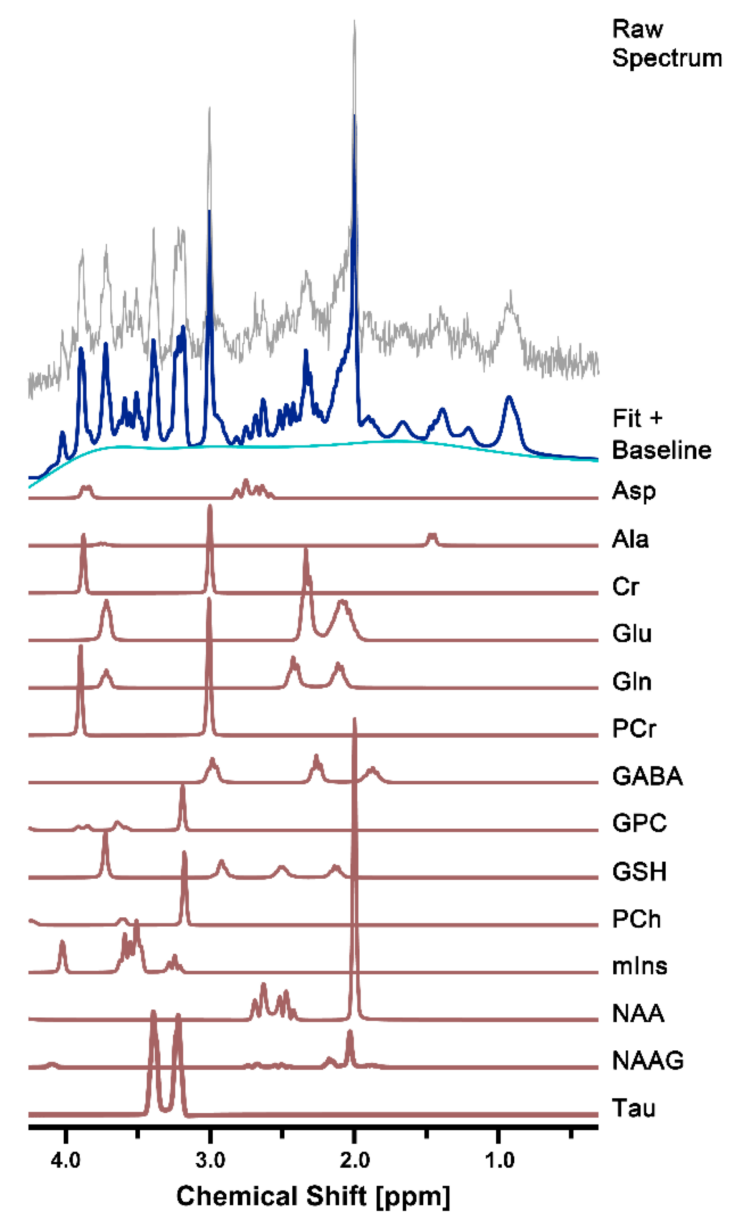

Figure 2. Representative in vivo ${ }^{1} \mathrm{H}$ MR spectra in the right hippocampus of cuprizone-treated rats. The figure shows the raw spectrum (gray), fitted spectrum (navy), baseline (light blue), and 14 individual metabolite fits below (brown). Ala, alanine; Asp, aspartate; Cr, creatine; GABA, gamma-aminobutyric acid; Gln, glutamine; Glu, glutamate; GPC, glycerophosphocholine; GSH, glutathione; mIns, myo-inositol; NAA, N-acetylaspartate; NAAG, N-acetylaspartylglutamate; PCh, phosphocholine; $\mathrm{PCr}$, phosphocreatine; ppm, part per million; Tau, taurine.

Figure 3 illustrates the assessed cerebral metabolite concentrations and spectral CRLB values obtained from the hippocampal region of both groups. The independent $t$-test revealed significant differences in the cerebral metabolite concentrations between the two groups. The concentrations of GABA $(2.064 \pm 0.496 \mu \mathrm{mol} / \mathrm{g}$ vs. $2.538 \pm 0.153 \mu \mathrm{mol} / \mathrm{g}$; $p=0.019)$, Glu $(6.693 \pm 0.436 \mu \mathrm{mol} / \mathrm{g}$ vs. $7.387 \pm 0.269 \mu \mathrm{mol} / \mathrm{g} ; p=0.001)$, and Glx $(9.632 \pm 0.323 \mu \mathrm{mol} / g$ vs. $10.578 \pm 0.632 \mu \mathrm{mol} / g ; p=0.001)$ were significantly higher in CPR rats than in CTRL rats. The concentrations of mIns $(4.138 \pm 0.616 \mu \mathrm{mol} / \mathrm{g}$ vs. $3.132 \pm 0.324 \mu \mathrm{mol} / \mathrm{g} ; p=0.001)$ and $\mathrm{tCr}(6.590 \pm 0.298 \mu \mathrm{mol} / \mathrm{g}$ vs. $6.030 \pm 0.478 \mu \mathrm{mol} / \mathrm{g}$; $p=0.006)$ were significantly lower in CPR rats than in CTRL rats. 


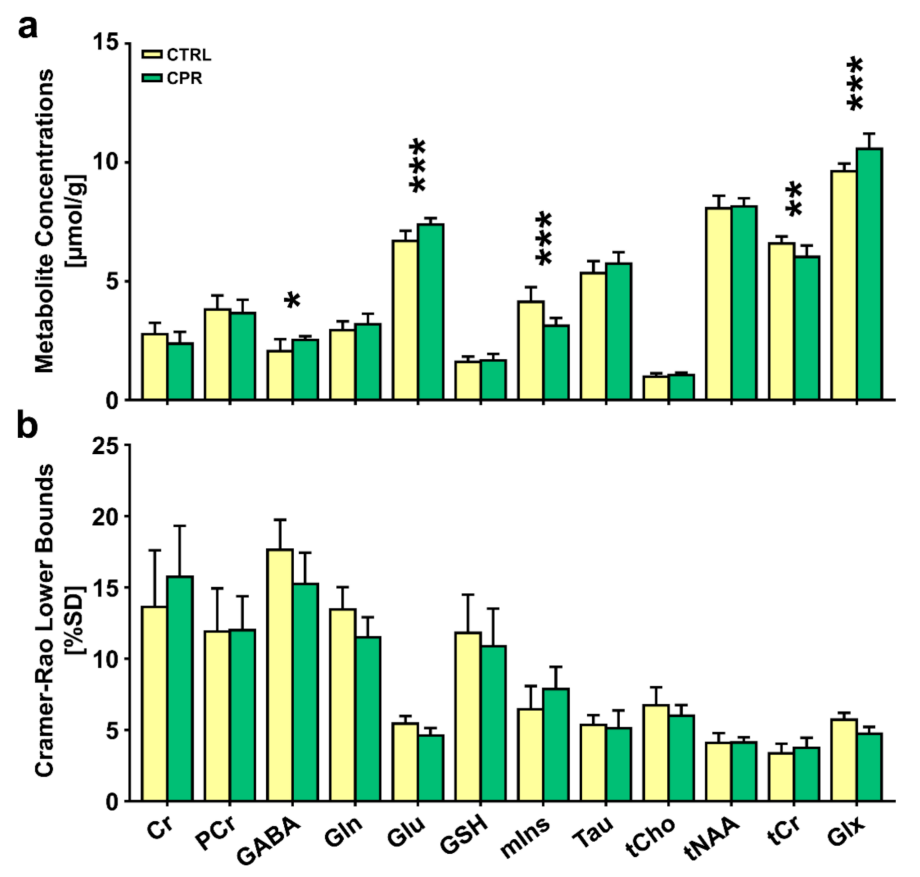

Figure 3. Bar graph indicating the mean cerebral metabolite concentrations (a) and Cramer-Rao lower bounds (CRLBs) (b) in the right hippocampal region of control (CTRL) and cuprizone-treated (CPR) rats, quantified using Linear Combination of Models software. The vertical lines on each of the bars indicate the $(+)$ standard deviation of the mean values. ${ }^{*} p<0.05 ;{ }^{* *} p<0.01$; ${ }^{* * *} p<0.005$. Cr, creatine; GABA, gamma-aminobutyric acid; Gln, glutamine; Glu, glutamate; Glx, Glu + Gln; GSH, glutathione; mIns, myo-inositol; PCr, phosphocreatine; SD, standard deviation; Tau, taurine; tCho (total Cho), GPC (glycerophosphocholine) + PCh (phosphocholine); tCr (total Cr), Cr + PCr; tNAA (total NAA), NAA (N-acetylaspartate) + NAAG (N-acetylaspartylglutamate).

Figure 4 illustrates the selected metabolite ratios of interest obtained from the hippocampal region of both groups. The Glx/tCr $(1.465 \pm 0.097$ vs. $1.758 \pm 0.091 ; p<0.001)$, $\mathrm{Glu} / \mathrm{tCr}(1.018 \pm 0.090$ vs. $1.231 \pm 0.094 ; p<0.001)$, and GABA $/ \mathrm{tCr}(0.314 \pm 0.076$ vs. $0.422 \pm 0.033 ; p=0.002)$ ratios in CPR rats were significantly higher than those in CTRL rats.

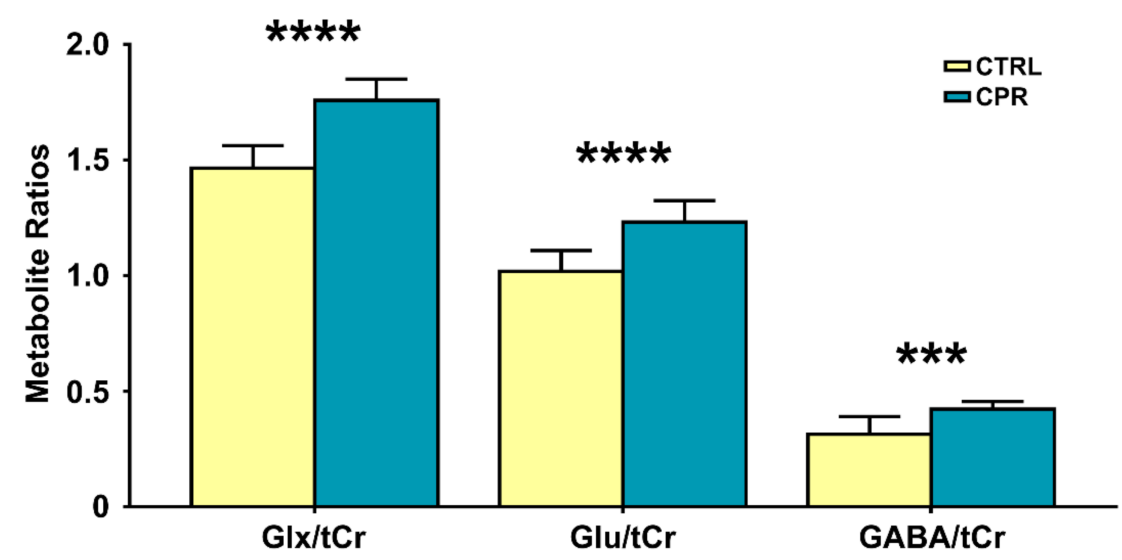

Figure 4. Bar graph showing the mean cerebral metabolite ratios in the right hippocampal region of the control (CTRL) and cuprizone-treated (CPR) rats. The vertical lines on each of the bars indicate the (+) standard deviation of the mean values. ${ }^{* * *} p<0.005 ;{ }^{* * * *} p<0.001$. GABA, gamma-aminobutyric acid; Glx, Glu (glutamate) + Gln (glutamine); tCr (total Cr), Cr (creatine) + PCr (phosphocreatine) 


\section{Discussion}

To date, numerous studies have investigated the extensive hippocampal demyelination seen in MS patients and animal models, in parallel with inflammation, microglia, and macrophage activation, which are strongly related to cognitive defects $[7,23,24]$. Notably, cerebral demyelination in the hippocampal region is considered a key feature in MS [7]. However, the underlying mechanisms of cuprizone-induced oligodendrocyte death and hippocampal damage caused by demyelination have not been well-revealed $[9,11]$. For these reasons, the present study demonstrates how axonal demyelination affects cerebral metabolites in the GM of the hippocampal region, quantified using high-resolution proton MR spectra.

In the present study, the concentrations of GABA, Glu, mIns, tCr, and Glx in the hippocampus of $\mathrm{CPR}$ rats were significantly altered compared to those in the hippocampus of CTRL rats. In addition, the $\mathrm{Glx} / \mathrm{tCr}$, $\mathrm{Glu} / \mathrm{tCr}$, and $\mathrm{GABA} / \mathrm{tCr}$ ratios were statistically higher in CPR rats than in CTRL rats. These findings suggest that neurochemical abnormalities are present in the hippocampal region of cuprizone-treated rats.

Previous clinical ${ }^{1} \mathrm{H}$ MRS studies have consistently shown a significant decrease in NAA concentrations and NAA/Cr ratios in the lesions of patients with MS [25,26]. The significant decrease in NAA concentrations is possibly representative of axonal damage and neuronal degeneration [27]. However, the present study showed that NAA concentrations were not significantly different between CPR and CTRL rats.

In our study, compared to CTRL rats, CPR rats exhibited significantly higher Glu concentrations and $\mathrm{Glu} / \mathrm{tCr}$ ratios in the hippocampal region. In addition, the statistically significant difference in Glx concentrations and Glx/tCr ratios might reflect the significant difference in Glu concentrations. Previous studies have indicated that the increased concentrations of Glu in acute MS lesions may be related to glutamate excitotoxicity induced by neuronal inflammation [13,27]. The oligodendrocytes in myelinating axons are especially vulnerable to increased tissue glutamate concentration and excitotoxicity [23]. The death of oligodendrocytes in the CNS is accompanied by microglial and macrophage activation, astrogliosis, and inflammatory cytokine release [28-30]. In particular, large quantities of Glu are produced and released by activated macrophages and microglial cells [27,31]. Therefore, increased Glu concentration in the demyelinated hippocampus may lead to Glu excitotoxicity, possibly due to neuronal inflammation and microglial and macrophage activation.

GABA is a principal neurotransmitter and is naturally present in relatively lower concentrations in the brain than other metabolites [32]. In particular, the non-invasive measurements of GABA concentration have limited reliability due to severely overlapping peaks (NAA, Glu, Gln, and $\mathrm{Cr}$ ) in the narrow chemical shift, and it is difficult to isolate it at a main magnetic field below $3 \mathrm{~T}$ in strength [33]. For these reasons, studies on the detection of cerebral GABA concentrations in vivo using ${ }^{1} \mathrm{H}$ MRS in patients with MS and animal models are sparse $[13,34,35]$. To date, only a few clinical studies in patients with MS have shown significantly altered GABA concentrations in the hippocampus [36,37], posterior cingulate cortex [33,36], parietal lobe [38], and sensorimotor cortex [38,39] using the Mescher-Garwood (MEGA)-PRESS editing technique.

The present study found significantly higher GABA concentrations and GABA/tCr ratios in the hippocampus of CPR rats than in the hippocampus of CTRL rats. According to previous in vitro studies, GABA and related receptors mainly exist in neurons, glial cells, and immune cells [40,41]. Numerous studies have demonstrated the immunosuppressant and anti-inflammatory properties of elevated GABA concentrations in patients with MS and animal models of neuro-inflammatory damage [38,40,42,43]. Thus, higher GABA concentrations and ratio values may reflect the corrective response to alleviate neuronal inflammation in the hippocampal region following cuprizone-induced demyelination.

Adenosine triphosphate (ATP) is the main source of energy for cell metabolism and is involved in cellular processes in the brain parenchyma [44]. In the presence of ATP, which is generated by oxidative phosphorylation in the mitochondria, creatine kinase (CK) catalyzes 
the reversible transphosphorylation between ATP and Cr to ADP and PCr [45]. These reactions can help balance the levels of phosphorylated and non-phosphorylated substrates and stabilize the energy supply system [46]. Previous studies have demonstrated that the $\mathrm{CK}$ isoform and $\mathrm{Cr}$ can protect mitochondrial permeability transition pores and, thus, have an important anti-apoptotic effect [47]. Moreover, CK and $\mathrm{Cr}$ help inhibit the generation of reactive oxygen species (ROS) within the mitochondria by facilitating the recycling of adenosine diphosphate during periods of increased glucose utilization [48]. In the present study, CPR rats exhibited significantly lower $\mathrm{tCr}$ concentrations in the hippocampal region than those in CTRL rats. Although there were no significant differences in $\mathrm{Cr}$ and $\mathrm{PCr}$ concentrations between the two groups, a trend for lower concentrations in CPR rats was observed. A previous study suggested that decreased $\mathrm{tCr}$ concentrations may reflect an energy deficit in brain neurons, possibly due to mitochondrial dysfunction [49]. Therefore, the significantly lower $\mathrm{tCr}$ concentrations found in this study might be due to mitochondrial dysfunction caused by cuprizone-induced demyelination in the hippocampus.

Our key finding was that mIns concentrations in the hippocampal region were significantly lower in CPR rats than in CTRL rats. Previous studies have suggested that mIns originates from intracellular astrocyte stores and is considered a key marker of astrocytic activation and proliferation [50-52]. Moreover, decreased mIns concentrations might reflect astrocytic necrosis with hypo-osmolarity [53] and oligodendrocyte injury [51]. Fernando et al. reported that significantly higher mIns concentrations were observed in normal-appearing white matter (NAWM) of clinically isolated syndrome patients than in NAWM of healthy subjects [54]. They suggested that the higher mIns concentrations may be due to the extensively increased gliosis in demyelinated lesions and NAWM [54]. Llufriu et al. suggested that decreased NAA concentrations and increased mIns concentrations indicate reduced axonal integrity and increased gliosis, respectively. Therefore, the mIns/tNAA ratio can be useful for predicting brain atrophy and sustained clinical progression $[50,52,54]$. Although the present study found no significant difference in tNAA concentrations between the two groups, alterations in mIns concentrations may reflect astrocytic necrosis and astrogliosis, which have cardinal importance in the progression of MS [52].

Our study has some limitations. The present study examined only one region of the hippocampus and thus cannot suggest multi-regional changes and distributions in the neurochemical profile. To address these limitations, further studies should investigate how to visualize and quantify the distribution of metabolite changes based on the molecular process in vivo. In recent years, numerous studies have been proposed for detecting neurochemical signals such as Glu [55], mIns [56], Cr [57], and GABA [19] compounds, using the chemical exchange saturation transfer (CEST) technique. CEST imaging is a novel contrast enhancement technique that enables the indirect measurement of molecules with exchangeable solute protons [58]. Thus, CEST imaging with specific metabolites will be suitable for better understanding the molecular mechanism of cerebral demyelination in our future studies.

In our early study, we did not examine long-term changes in brain metabolites in an animal model of cuprizone-induced demyelination and remyelination. Therefore, we cannot provide neurochemical information on the effects of long-term demyelination or the evaluation of the remyelination process. Hence, additional studies are needed to examine the changes in metabolites related to therapeutics efficacy that can accelerate remyelination and neuronal recovery.

\section{Conclusions}

In summary, to explore the neurochemical profile of cuprizone-induced demyelination in the hippocampus, we conducted an in vivo ${ }^{1} \mathrm{H}$ MRS study at $7 \mathrm{~T}$. The present study highlights GABA, Glu, Glx, $\mathrm{tCr}$, and mIns concentrations as in vivo measures that are of potential relevance in studying hippocampal demyelination. Therefore, several significantly altered metabolites are possibly utilized as a neuronal marker in cuprizone-induced 
demyelination, and these findings might have cardinal importance in the progression of MS.

Author Contributions: Conceptualization, D.-W.L. and D.-H.L.; methodology, J.-I.K., C.-W.W., and J.K.K.; validation, D.-W.L., C.-W.W., H.H., K.W.K., D.-C.W., J.K.K., and D.-H.L.; formal analysis, D.-W.L. and D.-H.L.; resources, C.-W.W.; data curation, D.-W.L., J.-I.K., C.-W.W., and D.-H.L.; writingoriginal draft preparation, D.-W.L., J.-I.K., C.-W.W., H.H., D.-C.W., and D.-H.L.; writing-review and editing, D.-W.L., J.-I.K., H.H., D.-C.W., and D.-H.L.; visualization, K.W.K.; supervision, D.-C.W., K.W.K., J.K.K., and D.-H.L.; project administration, D.-W.L. and D.-H.L.; funding acquisition, D.-W.L. All authors have read and agreed to the published version of the manuscript.

Funding: This work was supported by the National Research Foundation of Korea (NRF) grant funded by the Korea Government (Ministry of Science and ICT, MSIT) (No. 2018R1C1B6004521).

Institutional Review Board Statement: The study was conducted according to the guidelines of the Declaration of Helsinki. All animal care and experiments were conducted with the approval of the Animal Care and Use Committee of Asan Medical Center of the University of Ulsan Medical School (approval date: 10-12-2018; permit code: 2018-13-271).

Data Availability Statement: The data that support the findings of this study are available from the corresponding author upon reasonable request.

Conflicts of Interest: The authors declare no conflict of interest.

\section{References}

1. Koutsoudaki, P.N.; Skripuletz, T.; Gudi, V.; Moharregh-Khiabani, D.; Hildebrandt, H.; Trebst, C.; Stangel, M. Demyelination of the hippocampus is prominent in the cuprizone model. Neurosci. Lett. 2009, 451, 83-88. [CrossRef] [PubMed]

2. Papadopoulos, D.; Dukes, S.; Patel, R.; Nicholas, R.; Vora, A.; Reynolds, R. Substantial archaeocortical atrophy and neuronal loss in multiple sclerosis. Brain Pathol. 2009, 19, 238-253. [CrossRef]

3. Varga, E.; Pandur, E.; Abrahám, H.; Horváth, A.; Ács, P.; Komoly, S.; Miseta, A.; Sipos, K. Cuprizone Administration Alters the Iron Metabolism in the Mouse Model of Multiple Sclerosis. Cell. Mol. Neurobiol. 2018, 38, 1081-1097. [CrossRef] [PubMed]

4. Mahad, D.H.; Trapp, B.D.; Lassmann, H. Pathological mechanisms in progressive multiple sclerosis. Lancet Neurol. 2015, 14, 183-193. [CrossRef]

5. Chiaravalloti, N.D.; DeLuca, J. Cognitive impairment in multiple sclerosis. Lancet Neurol. 2008, 7, 1139-1151. [CrossRef]

6. Ohgomori, T.; Jinno, S. Cuprizone-induced demyelination in the mouse hippocampus is alleviated by phytoestrogen genistein. Toxicol. Appl. Pharmacol. 2019, 363, 98-110. [CrossRef]

7. Liu, C.; Zhang, N.; Zhang, R.; Jin, L.; Petridis, A.K.; Loers, G.; Zheng, X.; Wang, Z.; Siebert, H.C. Cuprizone-Induced Demyelination in Mouse Hippocampus Is Alleviated by Ketogenic Diet. J. Agric. Food Chem. 2020, 68, 11215-11228. [CrossRef]

8. Kim, W.; Hahn, K.R.; Jung, H.Y.; Kwon, H.J.; Nam, S.M.; Kim, J.W.; Park, J.H.; Yoo, D.Y.; Kim, D.W.; Won, M.H.; et al. Melatonin ameliorates cuprizone-induced reduction of hippocampal neurogenesis, brain-derived neurotrophic factor, and phosphorylation of cyclic AMP response element-binding protein in the mouse dentate gyrus. Brain Behav. 2019, 9, 1-11. [CrossRef]

9. Klein, B.; Mrowetz, H.; Barker, C.M.; Lange, S.; Rivera, F.J.; Aigner, L. Age Influences Microglial Activation After CuprizoneInduced Demyelination. Front. Aging Neurosci. 2018, 10, 1-22. [CrossRef]

10. Denic, A.; Johnson, A.J.; Bieber, A.J.; Warrington, A.E.; Rodriguez, M.; Pirko, I. The relevance of animal models in multiple sclerosis research. Pathophysiology 2011, 18, 21-29. [CrossRef]

11. Bénardais, K.; Kotsiari, A.; Škuljec, J.; Koutsoudaki, P.N.; Gudi, V.; Singh, V.; Vulinović, F.; Skripuletz, T.; Stangel, M. Cuprizone [bis(cyclohexylidenehydrazide)] is selectively toxic for mature oligodendrocytes. Neurotox. Res. 2013, 24, 244-250. [CrossRef] [PubMed]

12. Matsushima, G.K.; Morell, P. The neurotoxicant, cuprizone, as a model to study demyelination and remyelination in the central nervous system. Brain Pathol. 2001, 11, 107-116. [CrossRef]

13. Orije, J.; Kara, F.; Guglielmetti, C.; Praet, J.; Van der Linden, A.; Ponsaerts, P.; Verhoye, M. Longitudinal monitoring of metabolic alterations in cuprizone mouse model of multiple sclerosis using $1 \mathrm{H}$-magnetic resonance spectroscopy. Neuroimage 2015, 114, 128-135. [CrossRef] [PubMed]

14. Laule, C.; Vavasour, I.M.; Kolind, S.H.; Li, D.K.B.; Traboulsee, T.L.; Moore, G.R.W.; MacKay, A.L. Magnetic resonance imaging of myelin. Neurotherapeutics 2007, 4, 460-484. [CrossRef] [PubMed]

15. Tkáč, I.; Gruetter, R. Methodology of 1H NMR spectroscopy of the human brain at very high magnetic fields. Appl. Magn. Reson. 2005, 29, 139-157. [CrossRef]

16. Tkáč, I.; Henry, P.G.; Andersen, P.; Keene, C.D.; Low, W.C.; Gruetter, R. Highly resolved in vivo 1H NMR spectroscopy of the mouse brain at 9.4 T. Magn. Reson. Med. 2004, 52, 478-484. [CrossRef]

17. Lee, D.W.; Chung, S.; Yoo, H.J.; Kim, S.J.; Woo, C.W.; Kim, S.T.; Lee, D.H.; Kim, K.W.; Kim, J.K.; Lee, J.S.; et al. Neurochemical changes associated with stress-induced sleep disturbance in rats: In vivo and in vitro measurements. PLoS ONE 2016, 11, 1-17. [CrossRef] 
18. Wang, A.M.; Pradhan, S.; Coughlin, J.M.; Trivedi, A.; Dubois, S.L.; Crawford, J.L.; Sedlak, T.W.; Nucifora, F.C.; Nestadt, G.; Nucifora, L.G.; et al. Assessing Brain Metabolism with 7 T Proton Magnetic Resonance Spectroscopy in Patients with First-Episode Psychosis. JAMA Psychiatry 2019, 76, 314-323. [CrossRef]

19. Lee, D.H.; Lee, D.W.; Kwon, J.I.; Kim, S.T.; Woo, C.W.; Kon Kim, J.; Won Kim, K.; Seong Lee, J.; Gon Choi, C.; Suh, J.Y.; et al. Changes to gamma-aminobutyric acid levels during short-term epileptiform activity in a kainic acid-induced rat model of status epilepticus: A chemical exchange saturation transfer imaging study. Brain Res. 2019, 1717, 176-181. [CrossRef]

20. Jansen, J.F.A.; Backes, W.H.; Nicolay, K.; Kooi, M.E. 1H MR spectroscopy of the brain: Absolute quantification of metabolites. Radiology 2006, 240, 318-332. [CrossRef]

21. Pfeuffer, J.; Tkáč, I.; Provencher, S.W.; Gruetter, R. Toward an in vivo Neurochemical Profile: Quantification of 18 Metabolites in Short-Echo-Time 1H NMR Spectra of the Rat Brain. J. Magn. Reson. 1999, 141, 104-120. [CrossRef] [PubMed]

22. Lee, D.H.; Woo, C.W.; Kwon, J.I.; Chae, Y.J.; Ham, S.J.; Suh, J.Y.; Kim, S.T.; Kim, J.K.; Kim, K.W.; Woo, D.C.; et al. Cerebral mapping of glutamate using chemical exchange saturation transfer imaging in a rat model of stress-induced sleep disturbance at 7.0T. J. Magn. Reson. Imaging 2019, 50, 1866-1872. [CrossRef] [PubMed]

23. Geurts, J.J.G.; Bö, L.; Roosendaal, S.D.; Hazes, T.; Daniëls, R.; Barkhof, F.; Witter, M.P.; Huitinga, I.; Van Der Valk, P. Extensive hippocampal demyelination in multiple sclerosis. J. Neuropathol. Exp. Neurol. 2007, 66, 819-827. [CrossRef] [PubMed]

24. Norkute, A.; Hieble, A.; Braun, A.; Johann, S.; Clarner, T.; Baumgartner, W.; Beyer, C.; Kipp, M. Cuprizone treatment induces demyelination and astrocytosis in the mouse hippocampus. J. Neurosci. Res. 2009, 87, 1343-1355. [CrossRef]

25. De Stefano, N.; Bartolozzi, M.L.; Guidi, L.; Stromillo, M.L.; Federico, A. Magnetic resonance spectroscopy as a measure of brain damage in multiple sclerosis. J. Neurol. Sci. 2005, 233, 203-208. [CrossRef]

26. De Stefano, N.; Filippi, M. MR spectroscopy in multiple sclerosis. J. Neuroimaging 2007, 17, 31-35. [CrossRef]

27. Srinivasan, R.; Sailasuta, N.; Hurd, R.; Nelson, S.; Pelletier, D. Evidence of elevated glutamate in multiple sclerosis using magnetic resonance spectroscopy at 3 T. Brain 2005, 128, 1016-1025. [CrossRef]

28. Taraboletti, A.; Walker, T.; Avila, R.; Huang, H.; Caporoso, J.; Manandhar, E.; Leeper, T.C.; Modarelli, D.A.; Medicetty, S.; Shriver, L.P. Cuprizone Intoxication Induces Cell Intrinsic Alterations in Oligodendrocyte Metabolism Independent of Copper Chelation. Biochemistry 2017, 56, 1518-1528. [CrossRef]

29. Messori, L.; Casini, A.; Gabbiani, C.; Sorace, L.; Muniz-Miranda, M.; Zatta, P. Unravelling the chemical nature of copper cuprizone. Dalt. Trans. 2007, 2112-2114. [CrossRef]

30. Buschmann, J.P.; Berger, K.; Awad, H.; Clarner, T.; Beyer, C.; Kipp, M. Inflammatory response and chemokine expression in the white matter corpus callosum and gray matter cortex region during cuprizone-induced demyelination. J. Mol. Neurosci. 2012, 48, 66-76. [CrossRef]

31. Piani, D.; Frei, K.; Do, K.Q.; Cuénod, M.; Fontana, A. Murine brain macrophages induce NMDA receptor mediated neurotoxicity in vitro by secreting glutamate. Neurosci. Lett. 1991, 133, 159-162. [CrossRef]

32. Swanberg, K.M.; Landheer, K.; Pitt, D.; Juchem, C. Quantifying the Metabolic Signature of Multiple Sclerosis by in vivo Proton Magnetic Resonance Spectroscopy: Current Challenges and Future Outlook in the Translation from Proton Signal to Diagnostic Biomarker. Front. Neurol. 2019, 10, 1173. [CrossRef] [PubMed]

33. Cao, G.; Edden, R.A.E.; Gao, F.; Li, H.; Gong, T.; Chen, W.; Liu, X.; Wang, G.; Zhao, B. Reduced GABA levels correlate with cognitive impairment in patients with relapsing-remitting multiple sclerosis. Eur. Radiol. 2018, 28, 1140-1148. [CrossRef] [PubMed]

34. Meknatkhah, S.; Dashti, P.S.; Raminfard, S.; Rad, H.S.; Mousavi, M.-S.; Riazi, G.H. The Changes in 1H-MRS Metabolites in Cuprizone-Induced Model of Multiple Sclerosis: Effects of Prior Psychological Stress. J. Mol. Neurosci. 2020. [CrossRef] [PubMed]

35. Praet, J.; Orije, J.; Kara, F.; Guglielmetti, C.; Santermans, E.; Daans, J.; Hens, N.; Verhoye, M.; Berneman, Z.; Ponsaerts, P.; et al Cuprizone-induced demyelination and demyelination-associated inflammation result in different proton magnetic resonance metabolite spectra. NMR Biomed. 2015, 28, 505-513. [CrossRef]

36. Cawley, N.; Solanky, B.S.; Muhlert, N.; Tur, C.; Edden, R.A.E.; Wheeler-Kingshott, C.A.M.; Miller, D.H.; Thompson, A.J.; Ciccarelli, O. Reduced gamma-aminobutyric acid concentration is associated with physical disability in progressive multiple sclerosis. Brain 2015, 138, 2584-2595. [CrossRef]

37. Gao, F.; Yin, X.; Edden, R.A.E.; Evans, A.C.; Xu, J.; Cao, G.; Li, H.; Li, M.; Zhao, B.; Wang, J.; et al. Altered hippocampal GABA and glutamate levels and uncoupling from functional connectivity in multiple sclerosis. Hippocampus 2018, 28, 813-823. [CrossRef]

38. Nantes, J.C.; Proulx, S.; Zhong, J.; Holmes, S.A.; Narayanan, S.; Brown, R.A.; Hoge, R.D.; Koski, L. GABA and glutamate levels correlate with MTR and clinical disability: Insights from multiple sclerosis. Neuroimage 2017, 157, 705-715. [CrossRef]

39. Bhattacharyya, P.K.; Phillips, M.D.; Stone, L.A.; Bermel, R.A.; Lowe, M.J. Sensorimotor cortex gamma-aminobutyric acid concentration correlates with impaired performance in patients with MS. Am. J. Neuroradiol. 2013, 34, 1733-1739. [CrossRef]

40. Bhat, R.; Axtell, R.; Mitra, A.; Miranda, M.; Lock, C.; Tsien, R.W.; Steinman, L. Inhibitory role for GABA in autoimmune inflammation. Proc. Natl. Acad. Sci. USA 2010, 107, 2580-2585. [CrossRef]

41. Vélez-Fort, M.; Audinat, E.; Angulo, M.C. Central role of GABA in neuron-glia interactions. Neuroscientist 2012, 18, 237-250. [CrossRef] [PubMed]

42. Crowley, T.; Fitzpatrick, J.M.; Kuijper, T.; Cryan, J.F.; O’Toole, O.; O’Leary, O.F.; Downer, E.J. Modulation of TLR3/TLR4 inflammatory signaling by the GABAB receptor agonist baclofen in glia and immune cells: Relevance to therapeutic effects in multiple sclerosis. Front. Cell. Neurosci. 2015, 9, 1-12. [CrossRef] [PubMed] 
43. Jin, Z.; Mendu, S.K.; Birnir, B. GABA is an effective immunomodulatory molecule. Amino Acids 2013, 45, 87-94. [CrossRef]

44. Erecinska, M.; Silver, I.A. ATP and Brain Function. J. Cereb. Blood Flow Metab. 1989, 9, 2-19. [CrossRef] [PubMed]

45. Da Silva, C.G.; Bueno, A.R.F.; Schuck, P.F.; Leipnitz, G.; Ribeiro, C.A.J.; Rosa, R.B.; Dutra Filho, C.S.; Wyse, A.T.S.; Wannmacher, C.M.D.; Wajner, M. Inhibition of creatine kinase activity from rat cerebral cortex by D-2-hydroxyglutaric acid in vitro. Neurochem. Int. 2004, 44, 45-52. [CrossRef]

46. Bessman, S. The Creatine-Creatine Phosphate Energy Shuttle. Annu. Rev. Biochem. 1985, 54, 831-862. [CrossRef] [PubMed]

47. Dolder, M.; Walzel, B.; Speer, O.; Schlattner, U.; Wallimann, T. Inhibition of the mitochondrial permeability transition by creatine kinase substrates. Requirement for microcompartmentation. J. Biol. Chem. 2003, 278, 17760-17766. [CrossRef]

48. Meyer, L.E.; Machado, L.B.; Santiago, A.P.S.A.; Da-Silva, W.S.; De Felice, F.G.; Holub, O.; Oliveira, M.F.; Galina, A. Mitochondrial creatine kinase activity prevents reactive oxygen species generation: Antioxidant role of mitochondrial kinase-dependent ADP re-cycling activity. J. Biol. Chem. 2006, 281, 37361-37371. [CrossRef]

49. Xuan, Y.; Yan, G.; Wu, R.; Huang, Q.; Li, X.; Xu, H. The cuprizone-induced changes in 1H-MRS metabolites and oxidative parameters in C57BL/ 6 mouse brain: Effects of quetiapine. Neurochem. Int. 2015, 90, 185-192. [CrossRef]

50. Ciccarelli, O.; Barkhof, F.; Bodini, B.; De Stefano, N.; Golay, X.; Nicolay, K.; Pelletier, D.; Pouwels, P.J.W.; Smith, S.A.; Wheeler-Kingshott, C.A.M.; et al. Pathogenesis of multiple sclerosis: Insights from molecular and metabolic imaging. Lancet Neurol. 2014, 13, 807-822. [CrossRef]

51. Ciccarelli, O.; Thomas, D.L.; De Vita, E.; Wheeler-Kingshott, C.A.M.; Kachramanoglou, C.; Kapoor, R.; Leary, S.; Matthews, L.; Palace, J.; Chard, D.; et al. Low Myo-inositol indicating astrocytic damage in a case series of neuromyelitis optica. Ann. Neurol. 2013, 74, 301-305. [CrossRef]

52. Llufriu, S.; Kornak, J.; Ratiney, H.; Oh, J.; Brenneman, D.; Cree, B.A.; Sampat, M.; Hauser, S.L.; Nelson, S.J.; Pelletier, D. Magnetic resonance spectroscopy markers of disease progression in multiple sclerosis. JAMA Neurol. 2014, 71, 840-847. [CrossRef] [PubMed]

53. Häussinger, D.; Laubenberger, J.; Vom Dahl, S.; Ernst, T.; Bayer, S.; Langer, M.; Gerok, W.; Hennig, J. Proton magnetic resonance spectroscopy studies on human brain Myo-inositol in hypo-osmolarity and hepatic encephalopathy. Gastroenterology 1994, 107, 1475-1480. [CrossRef]

54. Fernando, K.T.M.; McLean, M.A.; Chard, D.T.; MacManus, D.G.; Dalton, C.M.; Miszkiel, K.A.; Gordon, R.M.; Plant, G.T.; Thompson, A.J.; Miller, D.H. Elevated white matter myo-inositol in clinically isolated syndromes suggestive of multiple sclerosis. Brain 2004, 127, 1361-1369. [CrossRef] [PubMed]

55. Davis, K.A.; Nanga, R.P.R.; Das, S.; Chen, S.H.; Hadar, P.N.; Pollard, J.R.; Lucas, T.H.; Shinohara, R.T.; Litt, B.; Hariharan, H.; et al. Glutamate imaging (GluCEST) lateralizes epileptic foci in nonlesional temporal lobe epilepsy. Sci. Transl. Med. 2015, 7, 309ra161. [CrossRef] [PubMed]

56. Haris, M.; Cai, K.; Singh, A.; Hariharan, H.; Reddy, R. In vivo mapping of brain myo-inositol. Neuroimage 2011, 54, $2079-2085$. [CrossRef]

57. Kogan, F.; Haris, M.; Debrosse, C.; Singh, A.; Nanga, R.P.; Cai, K.; Hariharan, H.; Reddy, R. In vivo chemical exchange saturation transfer imaging of creatine (CrCEST) in skeletal muscle at 3T. J. Magn. Reson. Imaging 2014, 40, 596-602. [CrossRef]

58. Lee, D.W.; Woo, C.W.; Woo, D.C.; Kim, J.K.; Kim, K.W.; Lee, D.H. Regional mapping of brain glutamate distributions using glutamate-weighted chemical exchange saturation transfer imaging. Diagnostics 2020, 10, 571. [CrossRef] 